\title{
A Conceptual Design Tool for Resolving Conflicts Between Product Functionality and Environmental Impact
}

\author{
Jeffrey W. Herrmann \\ e-mail: jwh2@umd.edu
}

\author{
Linda C. Schmidt \\ e-mail: Ischmidt@umd.edu \\ Department of Mechanical Engineering, \\ University of Maryland, \\ College Park, MD 20742
}

Product development organizations are unwilling to compromise product functionality, unit cost, or time to market in order to create products that have less environmental impact than that required by regulations. Thus, designers may face a conflict between improving product functionality and reducing environmental impact. The design for environment $(D f E)$ tools currently available are inadequate with respect to helping designers determine how to resolve this conflict during the conceptual design phase. Designby-analogy is a promising conceptual design approach for this problem. Examples of products that simultaneously reduce environmental impact and improve product functionality can inspire designers to do likewise. The challenges are to generate the relevant knowledge and to organize it in an accessible DfE tool. This paper describes an approach for generating and organizing this knowledge, an analysis of successful products, and a table of successful designs. [DOI: 10.1115/1.4002144]

\section{Introduction}

Product development organizations are constantly redesigning their products to keep up with changes in technology, regulations, consumer preferences and to get ahead of market competition. During redesigns, organizations are interested in increasing the functionality of their products. Functionality includes all valuable results of a product's behavior in its use environment such as specific features, ergonomics, and capacity. During a redesign, it is also desirable to reduce the product's environmental impact (among other harmful effects) to satisfy consumer demand and existing and pending environmental regulations.

Design engineers understand the social benefits of a design for environment (DfE) program, but they are unsure of how to reduce the environmental impact of their products once the obvious changes in materials and processes are implemented. DfE programs begin with statements about the corporation's responsibility to preserve the environment and adhere to applicable environmental regulations. DfE programs may also include enterprise-wide energy conservation and recycling goals. For product development teams, typical DfE implementation plans disseminate documents, such as checklists, guidelines, and scorecards, that provide the engineer information on what needs to be done (i.e., which environmental metrics need to be improved). Product designers are clear on how to proceed when enforcing changes to more environmentally benign materials. Unfortunately, broad DfE guidelines do not provide any ideas on how to conceptualize a solution. In some product redesign cases, there are managementsponsored brainstorming sessions that can provide intellectual stimulation, but these sessions are limited to the experience of the attendees and are not a systematic way to realize a solution. Furthermore, design solutions that arise from DfE practices may not increase the functionality of a product. For instance, biodegradable materials may be less durable than the synthetic materials that need to be replaced. As a result, companies have been reluc-

Contributed by the Design Automation Committee of ASME for publication in the Journal of Mechanical Design. Manuscript received February 1, 2010; final manuscript received July 2, 2010; published online September 16, 2010. Assoc. Editor: Karthik Ramani. tant to prioritize DfE objectives with as much fervor as they do other key objectives such as product functionality, unit cost, and time to market [1].

There is evidence that organizations are interested in improving both product functionality and environmental impact. Matsushita and Toshiba [2,3] adopted versions of Factor X, which was developed using terms coined by both the Wuppertal Institute for Climate, Environment and Energy (Factor) and The World Business Council for Sustainable Development (Eco-Efficiency). Factor X was first advocated in the late 1990s as a technique for evaluating both the functional and environmental aspects of products and services.

Matsushita measures Factor $\mathrm{X}$ using the ratio of the improvement in "Quality of Life" to the reduction in "Environmental Impact." Toshiba calculates the eco-efficiency of a product as its value divided by its environmental impact and then calculates a product's Factor $\mathrm{T}$ as its eco-efficiency divided by the ecoefficiency of the benchmark product. While the specific values they use for calculations are different, both firms have adopted the idea that a product can be made more environmentally benign by increasing its functionality, decreasing its harmful effects, or both.

In general, product designers may face a contradiction or conflict between improving product functionality and reducing environmental impact. Automobile manufacturers, in particular, face the challenge of redesigning their vehicles (including performance and luxury models) to reduce their environmental impact without affecting their performance [4]. Designers need tools to resolve this conflict, especially in the conceptual design phase, when a small number of design decisions have a large impact on product functionality and environmental impact. Innovations and improvements beyond material substitutions are needed.

Given the number of possible conflicts and the vast number of problem domains in which such conflicts can occur, it is unreasonable to expect to create a predetermined set of solutions that can completely resolve all possible contradictions. To overcome this obstacle, other design methodologies, such as TRIZ, have utilized design by analogy. Design by analogy consists of mapping knowledge from one situation to another through a supporting system of relations or representations between situations and is well recognized for its innovative power [5].

This paper describes a conceptual design tool that, like design 
by analogy, provides designers with relevant knowledge about solutions that have been implemented in the past. With these ideas and their own ingenuity, designers can identify strategies to overcome specific contradictions between product functionality and environmental impact.

It is important to note that the proposed design tool does not attempt to address the problem of reducing a product's complete ecofootprint or overall sustainability. Instead, it focuses on the specific, practical, and critical task of resolving a conflict between an aspect of product functionality and an environmental impact.

This paper first reviews the relevant design literature and DfE strategies. It then discusses a methodology for identifying designs that have been used to resolve functional-environmental contradictions. Finally, the organization of this knowledge into a useful DfE conceptual design tool is discussed.

\section{Background}

2.1 Design for Environment Tools. Environmental objectives are increasingly important as companies seek to satisfy environmental regulations, to attract consumers who value environmentally benign products, and to be good corporate citizens. DfE is the systematic consideration of design performance with respect to environmental, health, and safety objectives over the full product life cycle [6-10]. Implementing DfE requires not only using DfE analysis tools but also changes to the product development process such as adding environmental criteria to the product specification to be effective $[11,12]$.

Design for " $\mathrm{X}$ " programs and practices, including design for manufacturing (DfM) and design for assembly (DfA), have developed over time as a natural response to improving profitability. These methodologies were first used by Ford and Chrysler to help with the design of wartime necessities during World War II [13]. The drivers for DfM and DfA are reducing the time to bring a product to market, reducing a product's cost and improving a product's quality. Since DfM and DfA practices have obvious benefits to profitability, guidelines such as reducing the number of total parts and exploiting part symmetry are now embedded in the engineering culture.

On the other hand, DfE is driven by regulations and social responsibility and does not always increase profitability. DfE practices such as designing for recyclability and using renewable resources are historically not part of most company's engineering culture. Thus, a barrier to the effective incorporation of DfE programs is the low priority that organizations often assign to environmental issues. Most organizations are not willing to compromise functionality, unit cost, or time to market in order to create products that have less environmental impact than required by regulations $[6,14]$. (The exceptions are those organizations, like Interface, Inc., that court environmentally conscious consumers.) Moreover, "even when motivated to design for the environment, product designers are unsure exactly how to proceed. They face an open-ended problem about which information is scarce" [14].

Consequently, manufacturing companies and academia have spent a great deal of effort developing tools to help designers create more environmentally benign products. There are a few problems associated with the DfE tools currently available [15] that prevent designers from realizing innovative solutions. First, most of the tools focus on determining which environmental aspect needs to be improved rather than how a designer can improve that aspect. Second, most tools require too much information to be useful during conceptual design. A tool that can be used earlier in the product development process will have more influence on the design. Finally, most DfE tools are focused solely on reducing the environmental impact of a product and neglect other important aspects such as product functionality.

Devanathan et al. [16] emphasized the importance of considering environmental issues during conceptual design. They proposed a novel tool called the function impact matrix, which combines tools for Eco-Design, such as life-cycle assessment, and tools for functional and customer requirements, such as quality function deployment. Their approach confirms that environmental improvements can be made without negatively affecting functional performance. Their function impact matrix identifies which aspect of the product needs to be improved but not how to improve that aspect.

Other design tools that come close to overcoming the aforementioned problems are the House of Environmental Quality and the Product Ideas Tree. The House of Environmental Quality highlights potential conflicts between functional and environmental criteria but does not provide the designer with any information on how to overcome the contradiction [15]. The product idea tree is a "diagram [that] provides a record and organization strategy for ideas to incorporate into a product concept generated during design brainstorming sessions where ideas are recorded by the most relevant design process stage and environmental impact category affected" [15]. The tool provides a structure for brainstorming but these sessions are limited to the experience of the attendees and are not a systematic way to realize a solution. Also, the tool considers only the environmental aspects of the product.

2.2 Design by Analogy and TRIZ. In design by analogy, the designer uses his own experience and relevant examples and applies them to the new problem. "In the past 25 years, analogy has assumed a central role in theories of problem solving and scientific discovery... Used in conjunction with domain-specific knowledge, analogy may enable the search process to be greatly abridged when patterns are noticed in the current problem state. Prestored knowledge can be evoked and used to plan the next steps toward solution of the problem, provide macros to replace whole segments of step-by-step search, or even suggest an immediate problem solution. The recognition mechanism (with its associated store of knowledge) is a key weapon in the arsenal of experts and a principle factor in distinguishing their performance in the domain of expertise from that of novices" [17].

Analogical thinking is one of the cognitive processes that designers use when searching for solutions to technical challenges such as imagining design improvements that also improve environmental impact. Research is underway to test the impact of providing seed ideas or cues to designers during the process of ideation that is critical to conceptual design. One group in the United Kingdom tested the value of providing idea stimulus to design teams in industry. They found that introducing stimuli in the form of TRIZ innovative principles supported the rate of ideation generation during brainstorming sessions and lead to less obvious ideas [18]. Work with student groups concluded that the nature of the provided stimulus was important on its ideation impact. This study found that the more disparate the stimulus is, the more difficult it seems to be for designers to use it; thus the context within which the cues are provided is important for success [19]. Another study with engineering students focused on the impact of lexical stimuli (words) on design generation and found that students tended to use the words as verbs, especially when the stimulus was seemingly unconnected to the design task [20]. The same lexical study found that the dichotomous stimulus (like that presented in the TRIZ method) led to concepts that were judged by raters to be more novel than other concepts. This research on ideation suggests that designers who consider cueing examples after determining some initial problem solving parameters may improve the quantity and quality of the concepts that they generate.

Furthermore, a design by analogy style conceptual design tool requires identifying examples that embody good solution characteristics. Once collected, examples must be organized for retrieval based on objectives relevant to the design challenge rather than presented in some more natural means of coding (e.g., application area and key mechanical principle). Finally, the tool must be able to extract the examples that embody the key solution objectives even if the example is very different from the original problem.

The theory of solving inventive problems (known by the Rus- 
sian acronym TRIZ) [21-25] defines inventive principles and processes used within different industries and provides tools for solving technical problems of varying complexities. These tools, including the contradiction matrix, provide designers with an incredible knowledge base [26].

When trying to improve an engineering parameter of a product, a designer can encounter situations where the improved concept causes another engineering parameter to become worse. This conflict (or contradiction) is undesirable and usually results in a tradeoff or compromise solution. Ideally, the designer would prefer a concept that improves the engineering parameter of interest without any other engineering parameters worsening. The techniques found in TRIZ help the designer resolve these types of design contradictions and achieve this goal.

The contradiction table, one of the most recognizable tools within TRIZ, consists of two sets in matrix form: engineering parameters and principles. An engineering parameter is a feature of a problem that can worsen or improve such as weight of a moving object, temperature, or reliability. The engineering parameters form the headings on the left side and top of the matrix with the left side corresponding to an improving parameter and the top side corresponding to a worsening parameter. A principle is a technique that has been used for solving a contradiction between certain parameters. (TRIZ offers 40 inventive principles, for example, segmentation, preliminary anti-action, and periodic action.) The principles that have been found to help resolve a particular conflict between two engineering parameters are located in the cell of the matrix where the two engineering parameters intersect.

Many researchers acknowledge the strengths of the TRIZ approach to improving design and have experimented with environmental adaptations of TRIZ [27-32]. Liu and Chen [27] developed a green innovation design method by analyzing the TRIZ contradiction matrix. The authors mapped TRIZ parameters to environmental goals and through frequency analysis of the contradiction matrix concluded that certain inventive principles are more likely to achieve specific environmental goals. This approach does not address conflicts between functionality and environmental impact, and the parameters in TRIZ do not thoroughly address all of the environmental parameters as discussed later in Sec. 5. Chang and Chen [28] present an eco-innovative example product for each of the 40 TRIZ inventive principles to highlight that the inventive principles can be used for eco-innovation. Low et al. [29] explored the applicability and adaptation of TRIZ to an ecocentered service solution. The authors conclude that TRIZ is better suited to generate product focused solutions rather than service oriented solutions because of its inability to handle multifaceted, multihierarchical situations. Jones and Harrison [30] investigated how TRIZ might be used and modified for Eco-Innovation through examination of environmentally innovative compact florescent lamps within Philips Lighting. To adapt TRIZ for use in Eco-Innovation, Jones and Harrison suggested studying environmental patents to extract principles for solving environmental contradictions. Kobayashi and Aoyama [31] proposed an expanded contradiction matrix that includes functionality parameters and environmental parameters on both the top and left sides of the matrix. They provide only a framework and one entry to the table based on an example provided in the paper. Sakao [32] proposed a methodology for environmentally conscious design that combines the use of life-cycle assessment (LCA), quality function deployment for the environment (QFDE), and TRIZ. This paper suggests that the current TRIZ contradiction matrix can easily handle functionality and environmental contradictions. However, the hair dryer example provided resolves a contradiction between two functionality requirements rather than a contradiction between a functionality and environmental requirement. Overall, however, this methodology is a very useful framework because it covers a wide range of the development process (from product planning to concept selection). The previous work, while an in- spiration to this paper, lacks the detailed research required to provide designers a systematic way to access design principles that have been used previously to resolve contradictions between functionality and environmental impact.

\section{Methodology}

The methodology used to develop this conceptual design tool proceeded through the following steps. First, a broad set of functionality and environmental parameters that are useful to designers during conceptual design were selected. Next, existing products that improve functionality and reduce environmental impact compared with the previous generation of that product were found. Finally, this information was organized into an improvementinnovation table. Sections 3.1-3.3 describe the details of these steps.

3.1 Selection of Environmental and Functionality Parameters. Before beginning the product search, we decided which environmental and functionality parameters should be used. For the environmental parameters, we used six of the seven ecoefficiency dimensions developed by the World Business Council for Sustainable Development [33]. This approach was also used by Chang and Chen [28] as a suitable standardized set of critical objectives for improving products. Listed below are the seven dimensions of eco-efficiency and their product level definitions:

1. Reduce the material intensity of goods and services: Reduce the amount of material used in the product and by the product (e.g., packaging, consumable accessories).

2. Reduce the energy intensity of goods and services: Reduce the energy consumed by the product.

3. Reduce toxic dispersion: Reduce the use of toxic chemicals or prevent toxic chemicals used from being emitted into the environment.

4. Enhance material recyclability: increase the amount of material that can be reused or recycled.

5. Maximize sustainable use of renewable resources: Increase the use of resources that can be replaced naturally at a rate that's greater than or equal to the rate of consumption.

6. Extend product durability: Increase the useful life of the product and include serviceability of the product.

7. Increase the service intensity of goods and services: Increase the focus on providing a service to satisfy customer needs rather than just what products to provide. Examples include shared use, multi-functionality, and upgradeability.

The Service Intensity dimension was excluded because it depends on infrastructure decisions that are made prior to a designer working on a product. Once it is decided that a product is needed to provide a service to satisfy a customer need, the designer will focus on the other six dimensions to improve the environmental impact of the product.

The set of engineering parameters used in the TRIZ contradiction matrix was a natural starting point for selecting the functionality parameters because of the link of this methodology to the TRIZ approach. We relied on Domb's list of definitions for the TRIZ engineering parameters [34]. We selected many but not all of the 39 TRIZ engineering parameters. We excluded the parameters that overlapped or directly related to environmental parameters. For instance, we excluded the "speed" parameter because it is very similar to the "productivity" and "loss of time" parameters and excluded the "ease of repair" parameter because it is related to the "product durability" environmental parameter. Additionally, when two parameters were used to cover both stationary and moving objects, we consolidated them into one parameter. For example, the "weight of moving object" and "weight of stationary object" parameters were combined. Appendix A lists the 39 TRIZ engineering parameters, the resulting 21 functionality parameters used in this research, a definition for each parameter [34], and an explanation of why certain parameters were not used. 
Table 1 Search terms used for environmental parameters

\begin{tabular}{ll}
\hline \hline Environmental parameter & Search terms \\
\hline Material intensity & Material reduction, light weight \\
Energy intensity & Energy efficient, less energy \\
Dispersion of toxic materials & Toxic, hazardous \\
Recyclability & Recycle, reuse \\
Renewable resource use & Renewable, biodegradable, sustainable \\
Product durability & Durability \\
\hline \hline
\end{tabular}

3.2 Product Search. The goal of the product search is to identify existing products that improve functionality and reduce environmental impact compared with the previous generation of that product. Because the term "improvement" is a comparative term, the product search sought products that could be compared with a prior embodiment (instead of "first of its kind" products).

We conducted two separate searches and have labeled the results of those searches as "patents" and "products." "Patents" are products that were specifically found in the U.S. patent database. "Products" are products that were found outside of the patent database in sources such as journal articles, online stores, and manufacturer's websites. In order to quickly narrow the search space, we decided to start each search by looking for environmental improvements, since there are fewer patents and products with environmental improvements than those with functionality improvements. We then analyzed each candidate that these searches identified to determine if it had a functionality improvement. If the candidate had both an environmental improvement and a functionality improvement, then the candidate was selected for the design tool. The following paragraphs give more information about each search.

We searched for patents in the U.S. patent database, which contains three different types of patents: utility patents, design patents, and plant patents. Utility patents are issued for the invention of a new and useful process, machine, manufacture, or composition of matter, or a new and useful improvement thereof. Design patents are issued for new, original, and ornamental designs for articles of manufacture. Plant patents are issued for new and distinct, invented or discovered asexually reproduced plants [35]. This research considered only utility patents because these patents must have a functional improvement.

Within the large set of utility patents, we searched for patents that provided environmental improvements. We used the NexisLexis Academic Database to search for environmental terms in the patent titles and abstracts (which describe the most important aspects of the patents). For each of the environmental parameters listed in Sec. 3.1, we developed equivalent search terms (shown in Table 1) that were likely to appear in the text of patents.

We searched the patents that were issued within a 1 year period (June 14, 2008, to June 14, 2009). We then analyzed the patents found from this search to determine their improvements. After analyzing 134 patents on the candidate list, we identified 80 patents that provide an improvement in functionality and a reduction in environmental impact (these are listed in Appendix B).

We searched for "products" in lists of products with environmental innovations. Although lists of "green" products are widely available, finding useful information about innovative products that are appropriate for the design tool was a more difficult task. For example, we could not just use the Energy Star certified products list because Energy Star only focuses on energy reduction and does not consider functionality improvement or decrement. We reviewed an article by Chang and Chen [28] that provided environmental product examples for all 40 TRIZ principles. Only 24 of the 40 products in the article were selected for the design tool. The products excluded either did not resolve a functionalenvironmental contradiction or were not thoroughly explained. We searched an online store that specializes in selling environmentally benign products [36]. Many of the products on the site (in- cluding items such as organic clothing) were simple substitutions of materials and did not provide any functionality improvement. Finally, we analyzed other innovative products that we found from manufacturers' websites and other sources that were discovered during the course of the research. Appendix B lists the 50 products found and references to more information about the products.

Both searches had to be limited in order to proceed to the analysis part of the research. This work is intended to include a sufficient number of examples to provide a starting point for future collaborative use and enhancement.

3.3 Improvement-Innovation Table. As each product was found from the product search, we identified the most relevant parameters (from those described in Sec. 3.1) to describe the functionality improvement and environmental impact reduction. We created a table (Table 2) of the functional-environmental pairs and placed each product into the appropriate cell in the table. Within the table, a number in parentheses (e.g., "(1)" or "(41)") refers to a patent in Appendix B, and a number with a leading pound sign (e.g., "\#15" or “\#23") is a product in Appendix B.

Some of the specific contradictions have many examples such as improving productivity and reducing energy intensity, while others have no examples. These result from the finite scope of the search and some aspects of the search. First, the search was focused on finding products that improved environmental impacts. We did not look for products that satisfied particular functionality improvements or specific functional-environmental contradictions. Second, some of the functionality parameters (e.g., productivity and adaptability or versatility) are broader than others. In general, we found fewer products for more specific functionality parameters such as illumination intensity and temperature.

\section{Patent and Product Examples}

This section lists some examples of the patents and products that were found in the product search, and each example describes the functionality improvement and the environmental impact reduction. (The numbers in front of each name refer to the patent and product lists in Appendix B.)

4.1 Patent (2): High-Efficiency Air Conditioning Apparatus. This invention relates to an improved air conditioning filter and cooling/heating coil that can easily be applied to new and existing air handling systems. The slant design of the components allows a more efficient heat transfer and particle entrapment than their conventional counterparts. By residing at an angle rather than $90 \mathrm{deg}$ in their air handling enclosures, and by virtue of their oblique prismatic construction, more filter media can be used and more heat transfer surface area can be incorporated without offering any substantial additional impediments to the flow of air. At angles of $45 \mathrm{deg}$, air friction of the coil and filter are reduced by $40-55 \%$. The functionality improvement is object generated harmful factors. In this case, dispersion of dust would be the harmful factor being improved. The environmental improvement is a reduction in energy intensity due to the more efficient heat transfer.

4.2 Patent (5): Reduced Material Fastener. This invention comprises a shank cross section for a reduced material fastener that is selected to provide a parting line. Having a parting line means that the fastener may be made using two opposing dies to cold form the cross section. In spite of some inventive effort over many years, nails with noncircular cross section shanks are not in widespread use. Part of the problem is the difficulty in manufacturing. Therefore, this invention provides a nail shank design that, compared with a round one, provides reduced weight but has the same or increased holding power and can be manufactured using practical forming apparatus. The improved functionality parameter is ease of manufacture and the environmental improvement is a reduction in material intensity. 
Table 2 Improvement innovation table. A number in parentheses (e.g., "(1)" or "(41)") refers to a patent in Appendix B, and a number with a leading pound sign (e.g., "\#15" or "\#23") is a product in Appendix B.

\begin{tabular}{|c|c|c|c|c|c|c|c|}
\hline & & \multicolumn{6}{|c|}{ Improving environmental parameter } \\
\hline & & $\begin{array}{l}\text { Reduce } \\
\text { material } \\
\text { intensity }\end{array}$ & $\begin{array}{c}\text { Reduce } \\
\text { energy } \\
\text { intensity }\end{array}$ & $\begin{array}{l}\text { Reduce } \\
\text { dispersion } \\
\text { of toxic } \\
\text { materials }\end{array}$ & $\begin{array}{l}\text { Increase } \\
\text { recyclability }\end{array}$ & $\begin{array}{l}\text { Increase } \\
\text { renewable } \\
\text { resource use }\end{array}$ & $\begin{array}{l}\text { Product } \\
\text { durability }\end{array}$ \\
\hline \multirow{21}{*}{ 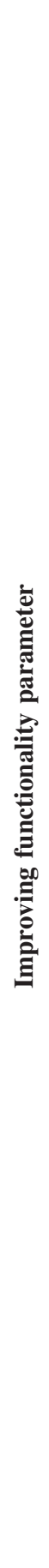 } & Weight & & $\# 12,(48)$ & \#16 & & & $\begin{array}{l}(68),(71), \\
(73),(74)\end{array}$ \\
\hline & Area & \#4 & & & & & \\
\hline & Volume & $\begin{array}{l}\# 3, \# 11, \\
\# 18,(27)\end{array}$ & & & & & \\
\hline & Stress or pressure & $(46)$ & $(32)$ & & & & $(15)$ \\
\hline & Shape & & & & & & $(20),(78)$ \\
\hline & Strength & $(22),(26)$ & (1) & & & & \#23 \\
\hline & Temperature & & $\begin{array}{l}\# 24,(35), \\
(38),(65)\end{array}$ & & (57) & & $(70)$ \\
\hline & Illumination intensity & & \#41, (41) & & & \#40 & (11) \\
\hline & Loss of substance & & & & & \#49 & $\# 30$ \\
\hline & Loss of information & \#42 & & & & & \\
\hline & Loss of time & & $\begin{array}{c}\# 25, \# 31, \\
\# 32, \# 35 \text {, } \\
\# 48,(3)\end{array}$ & $\# 13,(12)$ & & & $\# 37,(69)$ \\
\hline & Quantity of substance & & (4) & & & & \\
\hline & Reliability & $\# 27$ & $(34),(37)$ & $\# 6$, \#26 & & \#22 & $\# 5$ \\
\hline & $\begin{array}{l}\text { External harm affects } \\
\text { product }\end{array}$ & & & $(52)$ & (53) & $(54)$ & $\# 7$ \\
\hline & $\begin{array}{l}\text { Object generated } \\
\text { harmful factors }\end{array}$ & $\# 15,(24)$ & $(2)$ & (47) & (50) & $\begin{array}{l}\# 8, \# 46, \\
(10),(59)\end{array}$ & $\begin{array}{c}\# 2,(14), \\
(18),(72), \\
(75),(79), \\
(80)\end{array}$ \\
\hline & Ease of manufacture & $(5),(29)$ & & & (55) & (49) & $\begin{array}{l}\text { (17), (19), } \\
\text { (77) }\end{array}$ \\
\hline & $\begin{array}{l}\text { Adaptability or } \\
\text { versatility }\end{array}$ & $\begin{array}{l}\# 50,(21), \\
(23),(25)\end{array}$ & $\begin{array}{l}\# 9, \# 10, \\
\# 21,(33), \\
(40),(43)\end{array}$ & & & $\begin{array}{c}\# 39,(33), \\
\text { (61) }\end{array}$ & $\begin{array}{c}\# 1, \# 20, \\
\# 43,(16), \\
(67),(76)\end{array}$ \\
\hline & Device complexity & (28) & $(31),(42)$ & $(45)$ & & $(60)$ & \\
\hline & $\begin{array}{l}\text { Difficulty of detecting } \\
\text { and measuring }\end{array}$ & (30) & $\# 38$ & & & $\# 36$ & \\
\hline & Extent of automation & (7) & $\begin{array}{l}\# 29, \# 34, \\
\text { (36) }\end{array}$ & $\begin{array}{l}\# 28, \# 45 \text {, } \\
\text { (44) }\end{array}$ & & $\begin{array}{l}\# 17, \# 44, \\
(9),(66)\end{array}$ & \\
\hline & Productivity & (6) & $\begin{array}{c}\# 14, \# 19, \\
\# 33, \# 47, \\
(8),(13), \\
(39),(63), \\
(64)\end{array}$ & & $\begin{array}{c}(51),(56), \\
(58)\end{array}$ & (62) & \\
\hline
\end{tabular}

4.3 Product \#7: Self-Cleaning Exhaust Hood. This product actively deploys water vapors to intercept oil and dust before they reach the hood, whereas a traditional hood is equipped with a filter that needs to be regularly cleaned or else damage to the system may occur [28]. The functionality improvement is external harm affects product. In this case, the external harm is the oil and dust.
The environmental improvement is an extension of product durability through the removal of a service task that could lead to product failure.

4.4 Product \#31: Ecotoaster. A toaster that uses 34\% less energy than standard toasters, thanks to its rather clever autoclose 
lid that keeps the heat around the toast and prevents it from escaping through the top. It also toasts the bread quicker [36]. The functionality improvement is a loss of time and the environmental improvement is a reduction in energy intensity.

4.5 Product \#35 Ecokettle. This innovative kettle has a double chamber that directs a user to measure out exactly how much water they want to boil. By boiling only the water that is needed, users get their hot water quicker and use $31 \%$ less energy [36]. The functionality improvement is a loss of time and the environmental improvement is a reduction in energy intensity.

\section{Using the Improvement-Innovation Table}

The improvement-innovation table is a resource that provides designers examples of products that overcome contradictions between functionality and environmental performance.

The following steps are a way in which the improvementinnovation table can be used:

1. Identify and prioritize the functional and environmental parameters to be improved.

2. Identify and prioritize conflicts between these parameters (the priority of a conflict should reflect the priorities of the parameters).

3. Starting with the highest priority conflict, use the improvement-innovation table to find examples of solutions.

4. Use design-by-analogy to develop conceptual designs that resolve the conflict.

5. Repeat steps 3 and 4 as necessary to resolve other conflicts

To illustrate its use, consider the following hypothetical situation.

Step 1: Identify and Prioritize Parameters. The designer is working on the development of a new cooking oven. The designer has been provided with the following list of marketing and environmental requirements and their priority scores:

- quicker preheating (5)

- stylish design (stainless steel) (3)

- larger cooking capacity (3)

- reduce energy use (5)

- reduce the amount of material used (3)

The first three items on the list are functionality parameters. They are identified through market research and given priority scores based on customer feedback, the competitive market conditions, etc. The last two items on the list are environmental parameters. They are identified through either market research where consumers may be focused on a mainstream environmental issue such as energy efficiency or through an environmental impact analysis (i.e., life-cycle assessment). Because of this, setting the priority scores of environmental parameters becomes an interesting decision for companies. The customers may really care about the energy use of their oven but quantitatively the environmental impact of the energy use may be low compared with the amount of material used. It is up to the company to decide whether they focus more on a "perceived" environmental impact or a true environmental impact. The conceptual design tool is able to handle either decision.

Step 2: Identify and Prioritize Conflicts. From the list of oven requirements, the following conflicts in Table 3 have been identified and given priority scores based on the multiplication of the requirement priority scores. Some of the parameters will need to be translated into the parameters used in the improvementinnovation table. These translations are shown in parentheses. Furthermore, some of the conflicts that result may be between two functionality parameters, which can be handled by the TRIZ matrix.

Step 3: Use Improvement-Innovation Table. The conflict with the highest priority score is quicker preheating (loss of time) and reducing energy use, so this should be addressed first. This is
Table 3 Conflict priorities

\begin{tabular}{llc}
\hline \hline $\begin{array}{l}\text { Improving } \\
\text { functionality } \\
\text { parameter }\end{array}$ & $\begin{array}{l}\text { Improving } \\
\text { environmental } \\
\text { parameter }\end{array}$ & Priority score \\
\hline $\begin{array}{l}\text { Quicker preheating } \\
\text { loss of time) }\end{array}$ & Reducing energy use & 25 \\
\hline $\begin{array}{l}\text { Quicker preheating } \\
\text { loss of time) and }\end{array}$ & None & 15 \\
$\begin{array}{l}\text { larger cooking } \\
\text { capacity (volume) }\end{array}$ & & 15 \\
\hline $\begin{array}{l}\text { Larger cooking } \\
\text { capacity (volume) }\end{array}$ & Reducing energy use & \\
\hline $\begin{array}{l}\text { Larger cooking } \\
\text { capacity (volume) }\end{array}$ & Material intensity & 9 \\
\hline \hline
\end{tabular}

a conflict to the designer because the easy solution would be to apply more energy to preheat the oven quicker. Thus, the designer is interested in improving both loss of time and energy intensity. If the designer considers Table 2, he will find six patents and products that overcome this conflict. Let us examine \#31 (the ecotoaster) and \#35 (the ecokettle), which are described in Sec. 4.

Step 4: Use Design by Analogy. The ecotoaster utilizes a cover that retains heat when closed. Ovens already have a door that closes to retain heat but this could lead the designer to look into the general concept of improving heat retention by improving the door seals or improving the insulation in other areas. The ecokettle contains a feature that allows a user to heat only the amount of water that the user needs. Applying this to his oven could lead the designer to consider preheating only the volume within the oven that is needed for the task at hand. A solution that allows the cook to adjust the heated volume (based on the size of the food being cooked) would reduce the preheating time and reduce the amount of energy used. (This contradiction has been somewhat addressed by the invention of toaster ovens, which are much smaller than traditional ovens, but toaster ovens cannot expand to accommodate large items, so they are limited to heating only small items.)

Step 5: Repeat Steps 3 and 4 as Necessary. Once a conceptual design is found that resolves the highest priority contradiction, the other contradictions in the list need to be re-evaluated based on the new concept to see if they still exist or if any new contradictions have appeared. If a new contradiction appears with a higher priority than the contradiction resolved, then the new concept should not be used. In the example provided, the contradiction that was resolved had the highest possible priority so introducing a contradiction with a higher priority was not possible. If lower priority contradictions still exist, then the contradictions can be evaluated iteratively based on priority using the conceptual design tool to see if they can be resolved without introducing higher priority contradictions. It may not be possible to resolve all of the remaining contradictions but by addressing the higher priority contradictions first, the final concept will better address the most important requirements.

The procedure described above is similar to the methodology proposed by Sakao [32], which has the following steps: (1) Utilize LCA to determine scientifically based environmental impacts that may not be captured through traditional market research, (2) utilize a QFD style approach to capture and prioritize functional and environmental requirements and determine contradictions, and (3) utilize a TRIZ based tool for concept generation and evaluate the concept. For resolving functionality-environmental contradictions identified with Sakao's methodology, the conceptual design tool presented in this paper should be more effective than the contradiction matrix found within TRIZ because the parameters in TRIZ do not thoroughly address all of the environmental parameters. 
For example, one might argue that the TRIZ parameter "weight" could be used instead of "reducing material intensity" but weight would not encompass the amount of material used by a product during its useful life, which is part of "reducing material intensity."

\section{Summary and Conclusions}

Organizations are interested in reducing the environmental impacts of their products but not at the cost of product functionality or profitability. The DfE tools currently available to these organizations are limited in this situation because they focus on identifying the environmental aspect that needs to be improved (rather than suggesting how to improve the product), require too much information about the product design for the conceptual design phase, or consider only environmental aspects at the neglect of other important aspects such as functionality.
This paper presents a conceptual design tool that provides designers with knowledge on how to resolve functionalityenvironmental contradictions with very little information about the product design. This tool is a type of design by analogy, a well established and powerful innovation approach.

The limitation of the design tool is based on the number of example products that it currently contains. More examples will enhance the design tool. The authors will analyze additional candidate patents and will incorporate products that exhibit both an environmental and functionality improvement into the design tool.

In future work, we plan to examine each patent and product in the design tool and identify the general design principle that was used to overcome the functional-environmental contradiction. Then, we will create a new design tool that contains design principles rather than product examples. Long-term plans include creating an online collaborative version of the tool that a community of designers can use and continuously improve.

\section{Appendix A: Parameter Analysis}

\begin{tabular}{|c|c|c|c|}
\hline TRIZ parameter & $\begin{array}{l}\text { Functionality } \\
\text { parameter }\end{array}$ & Definition & Explanation \\
\hline \multicolumn{4}{|l|}{$\begin{array}{l}\text { 1-Weight of } \\
\text { moving object }\end{array}$} \\
\hline $\begin{array}{l}\text { 2-Weight of } \\
\text { stationary object }\end{array}$ & 1-Weight & The force that the body exerts on its support or suspension & $\begin{array}{l}\text { Consolidated into one parameter } \\
\text { for simplicity. }\end{array}$ \\
\hline \multicolumn{4}{|l|}{$\begin{array}{l}\text { 3-Length of } \\
\text { moving object }\end{array}$} \\
\hline $\begin{array}{l}\text { 4-Length of } \\
\text { stationary object }\end{array}$ & Not used & $\begin{array}{l}\text { Any one linear dimension, not necessarily the longest, is considered } \\
\text { a length }\end{array}$ & $\begin{array}{l}\text { Products and patents are analyzed } \\
\text { at a system level and length is too } \\
\text { detail oriented. }\end{array}$ \\
\hline \multicolumn{4}{|l|}{$\begin{array}{l}\text { 5-Area of moving } \\
\text { object }\end{array}$} \\
\hline $\begin{array}{l}\text { 6-Area of } \\
\text { stationary object }\end{array}$ & 2-Area & The part of a surface occupied by the object & $\begin{array}{l}\text { Consolidated into one parameter } \\
\text { for simplicity }\end{array}$ \\
\hline \multicolumn{4}{|l|}{$\begin{array}{l}\text { 7-Volume of } \\
\text { moving object }\end{array}$} \\
\hline $\begin{array}{l}\text { 8-Volume of } \\
\text { stationary object }\end{array}$ & 3-Volume & The cubic measure of space occupied by the object & $\begin{array}{l}\text { Consolidated into one parameter } \\
\text { for simplicity }\end{array}$ \\
\hline 9-Speed & Not used & The velocity of an object; the rate of a process or action in time. & $\begin{array}{l}\text { Similar to productivity and loss of } \\
\text { time }\end{array}$ \\
\hline 10-Force & Not used & $\begin{array}{l}\text { Force is any interaction that is intended to change an object's } \\
\text { condition. }\end{array}$ & Similar to stress or pressure \\
\hline $\begin{array}{l}\text { 11-Stress or } \\
\text { pressure }\end{array}$ & $\begin{array}{l}\text { 4-Stress or } \\
\text { pressure }\end{array}$ & Force per unit area. Also, tension. & Used \\
\hline 12-Shape & 5-Shape & The external contours, appearance of the system & Used \\
\hline $\begin{array}{l}\text { 13-Stability of the } \\
\text { object's } \\
\text { composition }\end{array}$ & Not used & $\begin{array}{l}\text { The wholeness or integrity of the system; the relationship of the } \\
\text { system's constituent elements. Wear, chemical decomposition, and } \\
\text { disassembly are all decreases in stability. Increasing entropy is } \\
\text { decreasing stability. }\end{array}$ & $\begin{array}{l}\text { Similar to environmental parameter } \\
\text { product durability }\end{array}$ \\
\hline 14-Strength & 6-Strength & $\begin{array}{l}\text { The extent to which the object is able to resist changing in response } \\
\text { to force. Resistance to breaking. }\end{array}$ & Used \\
\hline \multicolumn{4}{|l|}{$\begin{array}{l}15 \text {-Duration of } \\
\text { action by a } \\
\text { moving object }\end{array}$} \\
\hline $\begin{array}{l}\text { 16-Duration of } \\
\text { action by a } \\
\text { stationary object }\end{array}$ & Not used & $\begin{array}{l}\text { The time that the object can perform the action. Service life. Mean } \\
\text { time between failures is a measure of the duration of action. Also, } \\
\text { durability. }\end{array}$ & $\begin{array}{l}\text { Similar to environmental parameter } \\
\text { product durability }\end{array}$ \\
\hline 17-Temperature & 7-Temperature & The thermal condition of the object or system. & Used \\
\hline
\end{tabular}




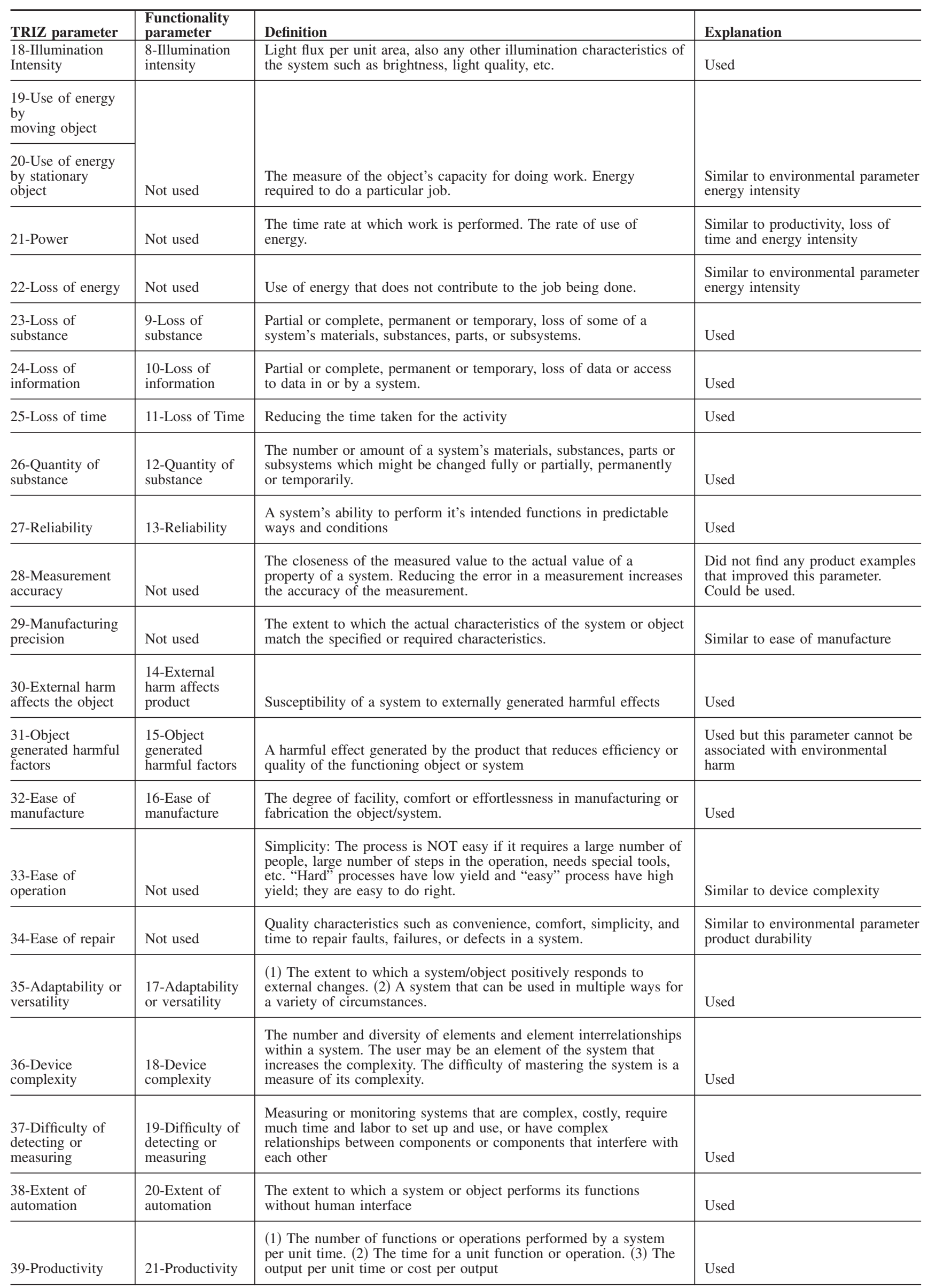




\begin{tabular}{|c|c|c|}
\hline Number & Patent title & Patent No. \\
\hline (1) & Method for controlling weld metal microstructure using localized controlled cooling of seam-welded joints & $7,540,402$ \\
\hline (2) & High efficiency conditioning air apparatus & $7,540,320$ \\
\hline (3) & Ice making machine, method and evaporator assemblies & $7,540,161$ \\
\hline (4) & Horizontal vibratory centrifuge apparatus & $7,534,358$ \\
\hline (5) & Reduced material fastener & $7,513,728$ \\
\hline (6) & Underbody car wash for home-use & $7,208,051$ \\
\hline (7) & Method and apparatus for flushing asphalt feeding devices & $7,544,253$ \\
\hline (8) & Low-fuel consumption and low pollution combustion system for supplying vehicle engine with mixture of fuel and oxygen & $7,543,577$ \\
\hline (9) & Solar powered engineless vehicle & $7,493,974$ \\
\hline (10) & Disposable grease filter for air filtration system and method of manufacturing same & $7,465,332$ \\
\hline (11) & Lamp for vehicle & $7,530,718$ \\
\hline (12) & Apparatus for applying disparate etching solutions to interior and exterior surfaces & $7,448,397$ \\
\hline (13) & Miniaturized waste heat engine & $7,430,865$ \\
\hline (14) & Coating compositions for bioactive agents & $7,544,673$ \\
\hline (15) & Quiet flexion/extension stop for orthopedic brace and orthopedic brace incorporating a quiet flexion/extension stop & $7,544,174$ \\
\hline (16) & Mobile truck tent of adjustable height & $7,540,555$ \\
\hline (17) & Providing freezing and thawing resistance to cementitious compositions & $7,531,584$ \\
\hline (18) & Stent with geometry determinated functionality and method of making the same & $7,527,644$ \\
\hline (19) & Spring spacer for a spring & $7,527,252$ \\
\hline (20) & Event chair construction & $7,510,244$ \\
\hline (21) & Portable and adjustable trailer assembly and method of use thereof & $7,543,842$ \\
\hline (22) & Light weight, stiffened, twist resistant, extruded vehicle axle & $7,537,290$ \\
\hline (23) & System of ultra light-weight demountable stations & $7,494,196$ \\
\hline (24) & Method of providing reinforcing members & $7,478,478$ \\
\hline$(25)$ & Interlocking box system & $7,467,502$ \\
\hline (26) & Low density, high rigidity disk drive suspension for high resonance frequency applications & $7,460,337$ \\
\hline (27) & High temperature superconducting degaussing system & $7,451,719$ \\
\hline (28) & Transmission & $7,448,292$ \\
\hline (29) & Mirror blank assembly & $7,429,114$ \\
\hline (30) & Cable tensiometer for aircraft & $7,424,832$ \\
\hline (31) & Energy efficient air handling system for cleanrooms & $7,539,601$ \\
\hline (32) & Polluting gas desulfurization apparatus, & $7,527,679$ \\
\hline (33) & Energy efficient dishwashing & $7,524,380$ \\
\hline (34) & Method and system for driving a plasma-based light source & $7,514,879$ \\
\hline (35) & Variable speed refrigeration system & $7,490,480$ \\
\hline (36) & Operation method of energy-saving fluid transporting machineries in parallel array with constant pressure & $7,480,544$ \\
\hline (37) & Universal mobile keyboard & $7,479,902$ \\
\hline (38) & Inkjet printer with low droplet to chamber volume ratio & $7,475,965$ \\
\hline (39) & Refrigeration and defrost control system & $7,454,918$ \\
\hline (40) & Energy efficient oxygen concentrator & $7,445,663$ \\
\hline (41) & Apparatus and method for improved illumination area fill & $7,438,447$ \\
\hline (42) & Pressurization system & $7,402,028$ \\
\hline (43) & Gas turbine system including vaporization of liquefied natural gas & $7,398,642$ \\
\hline (44) & Hazardous gas abatement system using electrical heater and water scrubber & $7,534,399$ \\
\hline$(45)$ & Method for surface cleaning & $7,514,015$ \\
\hline (46) & Simplistic approach to design of a reusable nozzle hub & $7,434,753$ \\
\hline (47) & Spill containment system and method & $7,428,911$ \\
\hline (48) & Automotive vehicle employing kinetic energy storage/reuse capability & $7,540,346$ \\
\hline (49) & Method for generating fracturing water & $7,527,736$ \\
\hline$(50)$ & $\begin{array}{l}\text { Method for manufacturing light barrier packaging material, light barrier packaging material, semi paper packaging material } \\
\text { and light barrier paper packaging container }\end{array}$ & $7,520,959$ \\
\hline$(51)$ & Device for reuse of plastic materials and paper fibers rejected in previous recycling & $7,520,455$ \\
\hline (52) & Materials and processes for reducing combustion by-products in a lubrication system for an internal combustion engine & $7,520,371$ \\
\hline (53) & Bathing pool assembly with water full of nanoscale ozone bubbles for rehabilitation & $7,488,416$ \\
\hline (54) & Water reuse in food processing & $7,470,172$ \\
\hline (55) & Vehicle seal with discontinuous alterating soft and rigid u-shaped segments and method of forming same & $7,467,495$ \\
\hline (56) & Process and apparatus for producing single-walled carbon nanotubes & $7,459,138$ \\
\hline (57) & Soundproof thermal shield & $7,445,084$ \\
\hline (58) & Waste water purification apparatus and waste water purification method including the regeneration of used coagulant & $7,410,573$ \\
\hline (59) & Solid biodegradable device for use in tissue repair & $6,391,049$ \\
\hline (60) & Stand-alone wind turbine system, apparatus, and method suitable for operating the same & $7,476,987$ \\
\hline$(61)$ & Autonomous water source & $7,467,523$ \\
\hline$(62)$ & Wind power system & $7,453,164$ \\
\hline (63) & Method and apparatus for simultaneous optimization of distributed generation and hydrogen production & $7,444,189$ \\
\hline (64) & Apparatus for aeration without significant agitation to deplete and biodegrade sludge & $7,425,269$ \\
\hline$(65)$ & Controlling standby power of low power devices & $7,401,241$ \\
\hline$(66)$ & Biodegradable pet mat & $7,392,765$ \\
\hline (67) & Rear suspension structure for large vehicles, & $7,530,585$ \\
\hline (68) & Pneumatic tire with high turnup locked bead construction, & $7,523,774$ \\
\hline (69) & Magnetic recording medium and magnetic recording device & $7,514,163$ \\
\hline (70) & Projection-type display devices including redundant laser sets & $7,510,284$ \\
\hline (71) & Tuning slide valve for intake manifold & $7,500,493$ \\
\hline (72) & Exterior component & $7,497,509$ \\
\hline (73) & Two piece sports equipment stick with internal truss construction and vented handle & 7485,054 \\
\hline (74) & Quick adjust ratcheting wrench with cam actuated clamping & $7,478,577$ \\
\hline (75) & Seat Rail for Vehicles & $7,475,861$ \\
\hline (76) & Multiphased and multidimensional wave converter & $7,443,047$ \\
\hline (77) & Casement window lock & $7,441,811$ \\
\hline (78) & Mounting structure for display unit in refrigerator & $7,430,111$ \\
\hline (79) & Flexible buoy & $7,421,965$ \\
\hline$(80)$ & Artificial nipple with reinforcement & $7,395,941$ \\
\hline
\end{tabular}




\begin{tabular}{|c|c|c|}
\hline No. & Product & Reference \\
\hline \#1 & Sectional sofa & Chang and Chen [27] \\
\hline$\# 2$ & Dual-layer tread tires & Chang and Chen [27] \\
\hline \#3 & High-efficiency cooling device for notebook computer & Chang and Chen [27] \\
\hline \#4 & Stacked chip scale packages & Chang and Chen [27] \\
\hline \#5 & Run-flat tire system & Chang and Chen [27] \\
\hline \#6 & Flashlight without batteries and bulbs & Chang and Chen [27] \\
\hline \#7 & Self-cleaning exhaust hood & Chang and Chen [27] \\
\hline \#8 & Washing Machine using centrifugal force & Chang and Chen [27] \\
\hline \#9 & Temperature controlled containers in low-temperature logistics & Chang and Chen [27] \\
\hline$\# 10$ & BMW's valvetronic engine & Chang and Chen [27] \\
\hline \#11 & Washing machine for single person & Chang and Chen [27] \\
\hline \#12 & Inverter welder & Chang and Chen [27] \\
\hline \#13 & Correction tape device & Chang and Chen [27] \\
\hline \#14 & Gasoline direct engine & Chang and Chen [27] \\
\hline \#15 & Active noise control & Chang and Chen [27] \\
\hline \#16 & Small-scale, high performance fuel cells for portable devices & Chang and Chen [27] \\
\hline$\# 17$ & Automatic faucet & Chang and Chen [27] \\
\hline \#18 & Virtual keyboard & Chang and Chen [27] \\
\hline \#19 & Vehicle hybrid system & Chang and Chen [27] \\
\hline \#20 & Air suspension system for cargo trucks & Chang and Chen [27] \\
\hline \#21 & Saab variable compression engine & Chang and Chen [27] \\
\hline \#22 & Ecodrive watch & Chang and Chen [27] \\
\hline$\# 23$ & M-wood & Chang and Chen [27] \\
\hline \#24 & Induction heat variable pressure boiling rice cooker & Chang and Chen [27] \\
\hline \#25 & Induction heat variable pressure boiling rice cooker & Chang and Chen [27] \\
\hline \#26 & Wind up radio & Nigel's Eco-Store [34] \\
\hline \#27 & Staple free stapler & http://www.greenhome.com/products/office/office_supplies/107970/ \\
\hline \#28 & Solar vent & http://store.sundancesolar.com/ststsove.html \\
\hline \#29 & Intellipanel-power strip with stand-by power reduction & Nigel's Eco-Store [34] \\
\hline \#30 & Battery wizard & Nigel's Eco-Store [34] \\
\hline \#31 & Eco toaster & Nigel's Eco-Store [34] \\
\hline \#32 & Energy saving gas net & Nigel's Eco-Store [34] \\
\hline \#33 & Radiator booster & Nigel's Eco-Store [34] \\
\hline \#34 & Radiator booster & Nigel's Eco-Store [34] \\
\hline \#35 & Eco kettle & Nigel's Eco-Store [34] \\
\hline \#36 & Shower coach shower timer & Nigel's Eco-Store [34] \\
\hline \#37 & Moon cup & Nigel's Eco-Store [34] \\
\hline \#38 & Energy elite wireless smart meter & Nigel's Eco-Store [34] \\
\hline \#39 & Sloan Valve Co. Uppercut ${ }^{\mathrm{TM}}$ flushometer & http://www.mbdc.com/c2c/itemDetails.php?item $=156$ \\
\hline$\# 40$ & Alcoa, Inc. Kawneer inlighten ${ }^{\circledR}$ light shelf & http://www.mbdc.com/c2c/itemDetails.php?item $=245$ \\
\hline \#41 & Moonlight-low energy night light & Nigel's Eco-Store [34] \\
\hline \#42 & Digital camera & $\begin{array}{l}\text { http://www.mnn.com/technology/research-innovations/stories/ } \\
\text { top-ten-eco-innovations-for-a-better-planet?page }=1\end{array}$ \\
\hline \#43 & USB rechargeable batteries & http://www.usbcell.com/ \\
\hline \#44 & Solar breeze pool cleaner & http://ecogadget.net/2007/12/24/the-solar-breeze-robot-vacuum-for-your-pool/ \\
\hline \#45 & Hg ionic toothbrush & Nigel's Eco-Store [34] \\
\hline \#46 & Bamboo socks & Nigel's Eco-Store [34] \\
\hline \#47 & Heatkeeper radiator panels & Nigel's Eco-Store [34] \\
\hline \#48 & Dryer balls & Nigel's Eco-Store [34] \\
\hline \#49 & Briquette maker & Nigel's Eco-Store [34] \\
\hline \#50 & Sharpie twin tip pen & $\begin{array}{l}\text { http://www.sharpie.com/enUS/Product// } \\
\text { Sharpie_Twin_Tip_Permanent_Marker.html }\end{array}$ \\
\hline
\end{tabular}

\section{References}

[1] Alexander, J., 2007, "Environmental Sustainability Versus Profit Maximization: Overcoming Systemic Constraints on Implementing Normatively Preferable Alternatives,” J. Bus. Ethics, 76(2), pp. 155-162.

[2] Matsushita Group, 2005, "Factor X: Aiming for Harmonious Coexistence Between Lifestyles and the Global Environment," http://panasonic.co.jp/eco/en/ factor_x/factor2005e.pdf

[3] Toshiba Group, 2006, "A New Indicator for Products: Factor T," http:// www.toshiba.co.jp/env/en/products/img/FactorT_E.pdf

[4] Brown, W., 2009, "Fantasy Ride's Technology Could Trickle Down," Washington Post Online, http://www.washingtonpost.com/wp-dyn/content/article/ 2009/10/09/AR2009100903234.html

[5] Linsey, J. S., Laux, J., Clauss, E. F., Wood, K. L., and Markman, A. B., 2007, "Effects of Analogous Product Representation on Design-by-Analogy," International Conference on Engineering Design, Paris, Aug. 28-31.

[6] Handfield, R. B., Melnyk, S. A., Calantone, R. J., and Curkovic, S., 2001, "Integrating Environmental Concerns Into the Design Process: The Gap Between Theory and Practice,” IEEE Trans. Eng. Manage., 48(2), pp. 189-208.

[7] Fiksel, J., 1996, Design for Environment: Creating Eco-Efficient Products and Processes, McGraw-Hill, New York.

[8] Bras, B., 1997, "Incorporating Environmental Issues in Product Design and
Realization," Industry and Environment, 20(1-2), pp. 5-13; see http:// www.unep.fr/media/review/ie_home.htm.

[9] Ashley, S., 1993, "Designing for the Environment," Mech. Eng. (Am. Soc. Mech. Eng.), 115(3), pp. 53-55.

[10] Fitzgerald, D. P., Herrmann, J. W., Sandborn, P. A., Schmidt, L. C., and Gogoll, T. H., 2007, "Design for Environment (DfE): Strategies, Practices, Guidelines, Methods, and Tools," Environmentally Conscious Mechanical Design, M. Kutz, ed., Wiley, Hoboken, NJ.

[11] Fitzgerald, D. P., Herrmann, J. W., Sandborn, P. A., Schmidt, L. C., and Gogoll, T. H., 2008, "Constructing a Product Design for Environment Process," Handbook on Performability Engineering, K. B. Misra, ed., Springer, New York.

[12] Fitzgerald, D. P., Herrmann, J. W., Sandborn, P. A., Schmidt, L. C., and Gogoll, T. H., 2005, "Beyond Tools: a Design for Environment Process," International Journal of Performability Engineering, 1(2), pp. 105-120.

[13] Ramaswamy, S., 1998, A Survey of DFM Methods, Arizona State University, Tempe, AZ.

[14] Lenox, M., King, A., and Ehrenfeld, J., 2000, "An Assessment of Design-forEnvironment Practices in Leading US Electronics Firms," Interfaces, 30(3), pp. 83-94.

[15] Kutz, M., 2007, "Life-Cycle Design," Environmentally Conscious Mechanical Design, M. Kutz, ed., Wiley, Hoboken, NJ. 
[16] Devanathan, S., Ramanujan, D., Bernstein, W. Z., Zhao, F., and Ramani, K., 2010, "Integration of Sustainability Into Early Design Through the Function Impact Matrix," ASME J. Mech. Des., 132(8), p. 081004.

[17] Klahr, D., 2000, Exploring Science: The Cognition and Development of Discovery Processes, MIT, Cambridge, MA

[18] Howard, T., Culley, S., and Dekoninck, E., 2008, "Creative Stimulation in Conceptual Design: An Analysis of Industrial Case Studies,” ASME Paper No. DETC2008-49672.

[19] Tseng, I., Moss, J., Cagan, J., and Kotovsky, K., 2008, "Overcoming Blocks in Conceptual Design: The Effects of Open Goals and Analogical Similarity on Idea Generation," ASME Paper No. DETC2008-49276.

[20] Chiu, I., and Shu, L. H., 2008, "Effects of Dichotomous Lexical Stimuli in Concept Generation," ASME Paper No. DETC2008-49372.

[21] Mazur, G., 1995, "Theory of Inventive Problem Solving (TRIZ)," www.mazur.net/triz

[22] Hipple, J., 2004, "TRIZ: A New Approach to Inventive Problem Solving," http://www.innovation-triz.com/papers/perspective.doc

[23] Shulyak, L., 2009, "Introduction to TRIZ," http://www.aitriz.org/articles/ 40p_triz.pdf

[24] "TRIZ Patterns of Evolution of Technological Systems," http:// www.trizexperts.net/evolutionpatterns.htm

[25] Altshuller, G., 1999, Innovation Algorithm: TRIZ, Systematic Innovation, and Technical Creativity, Technical Innovation Center, Inc., Worcester, MA.

[26] Webb, A., 2002, "TRIZ: An Inventive Approach to Invention," Eng. Manage. J., 12(3), pp. 117-124.

[27] Liu, C.-C., and Chen, J. L., 2001, "Development of Product Green Innovation Design Method," Second International Symposium on Environmentally Con- scious Design and Inverse Manufacturing, Tokyo, Japan, Dec. 11-15, pp. 168 173.

[28] Chang, H.-T., and Chen, J. L., 2003, "Eco-Innovative Examples for 40 TRIZ Inventive Principles," The TRIZ Journal, pp. 1-16; see http://www.trizjournal.com/archives/2003/08/a/01.pdf.

[29] Low, M. K., Lamvik, T., Walsh, K., and Myklebust, O., 2000, "Product to Service Eco-Innovation: The TRIZ Model of Creativity Explored," Proceed ings of the 2000 IEEE International Symposium on Electronics and the Environment, San Francisco, CA, May 8-10, pp. 209-214.

[30] Jones, E., and Harrison, D., 2000, "Investigating the Use of TRIZ Tools in Eco-Innovation," http://www.triz-journal.com/archives/2000/09/b/index.htm

[31] Kobayashi, N., and Aoyama, A., 2004, "Design for Environment (DfE) Meth odology Using Novel VE-Based Product and Process Model, and TRIZ-Based Innovation Principles in Consideration of Product Lifecycle," Sixth International Conference on Foundations of Computer-Aided Process Design, Princeton, NJ, Jul. 11-16, pp. 283-286.

[32] Sakao, T., 2007, "A QFD-centered Design Methodology for Environmentally Conscious Product Design,” Int. J. Prod. Res., 45(18), pp. 4143-4162.

[33] Desimone, L. D., and Popoff, F., 2000, Eco-Efficiency: The Business Link to Sustainable Development, MIT, Cambridge, MA

[34] Domb, E., 1998, "The 39 Features of Altshuller's Contradiction Matrix," The TRIZ Journal, see http://www.triz-journal.com/archives/1998/11/d/index.htm.

[35] United States Patent and Trademark Office, 2000, "Types of Patents," http:// www.uspto.gov/go/taf/patdesc.htm

[36] Nigel's Eco-Store, “About Nigel's Eco Store," http://www.nigelsecostore.com/ acatalog/about_us.htm 